This article is licensed under the Creative Commons Attribution-NonCommercial 4.0 International License (CC BY-NC) (http://www.karger.com/Services/OpenAccessLicense). Usage and distribution for commercial purposes requires written permission.

\title{
Frontal Phonological Agraphia and Acalculia with Impaired Verbal Short-Term Memory due to Left Inferior Precentral Gyrus Lesion
}

\author{
Yasuhisa Sakurai $^{\mathrm{a}} \quad$ Emi Furukawa $^{\mathrm{b}}$ Masanori Kurihara ${ }^{\mathrm{a}, \mathrm{c}}$ \\ Izumi Sugimoto ${ }^{a}$ \\ ${ }^{a}$ Department of Neurology, Mitsui Memorial Hospital, Tokyo, Japan; ${ }^{b}$ Department of \\ Nephrology, Mitsui Memorial Hospital, Tokyo, Japan; 'Department of Neurology, \\ Graduate School of Medicine, University of Tokyo, Tokyo, Japan
}

\section{Keywords}

Acalculia · Frontal pure agraphia · Phonological agraphia - Verbal short-term memory ·

Working memory

\begin{abstract}
We report a patient with phonological agraphia (selective impairment of kana [Japanese phonetic writing] nonwords) and acalculia (mental arithmetic difficulties) with impaired verbal short-term memory after a cerebral hemorrhage in the opercular part of the left precentral gyrus (Brodmann area 6) and the adjacent postcentral gyrus. The patient showed phonemic paragraphia in five-character kana nonword writing, minimal acalculia, and reduced digit and letter span. Mental arithmetic normalized after 8 months and agraphia recovered to the normal range at 1 year after onset, in parallel with an improvement of the auditory letter span score from 4 to 6 over a period of 14 months and in the digit span score from 6 to 7 over 24 months. These results suggest a close relationship between the recovery of agraphia
\end{abstract}

1, Kanda-Izumi-cho, Chiyoda-ku

Tokyo 101-8643 (Japan)

E-Mail ysakurai-tky@umin.ac.jp 


\section{Case Reports in Neurology}

and acalculia and the improvement of verbal short-term memory. The present case also suggests that the opercular part of the precentral gyrus constitutes the phonological route in writing that conveys phonological information of syllable sequences, and its damage causes phonological agraphia and acalculia with reduced verbal short-term memory.

(C) 2018 The Author(s)

Published by S. Karger AG, Basel

\section{Introduction}

Phonological agraphia is an impaired ability to spell nonwords and a preserved ability to spell familiar words, either regular or irregular. Spelling errors in phonological agraphia are usually not phonologically correct, but have a visual resemblance to the intended word. It is assumed that phonological agraphia arises from damage to the phonological route that plays the role of phoneme-to-grapheme conversion. The neural substrate of phonological agraphia is the left perisylvian cortices, including the supramarginal gyrus, insula, and superior temporal gyrus [1]. It should be noted that these perisylvian cortices are connected with the arcuate fasciculus.

In the Japanese language, phonological agraphia presents as kana (Japanese phonetic writing) agraphia that is characterized by phonemic paragraphia for kana. Phonemic or literal paragraphia includes substitution, addition, or omission of kana characters. Kana paragraphic errors are observed in kana words - much more in kana nonwords. This is why kana word agraphia is comparable to phonological agraphia (selective impairment of nonword spelling) in Western countries.

We herein report a patient with phonological agraphia, mental arithmetic difficulties, and verbal short-term memory impairment after subcortical hemorrhage in the opercular part of the left precentral gyrus. We followed these deficits for 2 years. The aim of the present study was to clarify how his writing disorder and acalculia were correlated with reduced verbal short-term memory.

\section{Materials and Methods}

\section{Patient Profile}

A right-handed, 58-year-old man, a freelance writer and graduate of a prestigious university, felt difficulty finding words in January 2016. He had a past history of unstable angina, hypertension, and polycythemia vera, and had taken aspirin $100 \mathrm{mg}$ per day. He visited our emergency department and was hospitalized with a diagnosis of cerebral hemorrhage on CT. Neurological examination showed a minor degree of right facial and limb hemiparesis and hemisensory loss, and dysarthria. He did not articulate properly, and said or wrote some digits wrongly. MRI performed 13 days after onset revealed a hyperintense area under the opercular part of the left precentral gyrus (Brodmann area 6) that extended upward under the postcentral gyrus (Fig. 1). Single photon emission computed tomography with a $99 \mathrm{mTc}-$ ethylcysteinate dimer (99mTc-ECD-SPECT) performed 15 days after onset showed a focal reduction of the cerebral blood flow in the lower part of the left sensorimotor cortex (Fig. 2). 
The patient underwent the following neuropsychological tests during 4-13 days after onset and a follow-up test from 6 to 24 months later.

\section{Neuropsychological Assessment}

Standard Neuropsychological Tests (Table 1)

The patient achieved high scores in the Wechsler Adult Intelligence Scale-III (WAIS-III), although his digit span forward score remained at 6. The Western Aphasia Battery (WAB, Japanese edition) did not show any abnormality.

Specific Neuropsychological Tests

Modality-Specific Digit Span and Letter/Character Span (Table 2). Digit or kana letter/character sequences were presented auditorily (usual digit or letter span forward) and visually with an Apple laptop computer using Psyscope X B57D software [2]. We adopted this computerized assessment to control the duration of presentation to be equal to that for auditory presentation ( 1 digit or letter/s). The duration of presentation was $500 \mathrm{~ms}$ with a 500-ms interval for each digit or letter sequence. The patient first saw a crosshair at the center of the 13-inch white display. With the examiner's "Start" signal, a digit or letter in black Helvetica font and 1-cm square in size, appeared at the center successively. The patient viewed the stimuli with the eyes positioned $50 \mathrm{~cm}$ away from the display. At the end of the presentation, the patient was asked to recall and orally state the digit or letter sequence from the beginning. The response time was not measured. The results for healthy controls around the same age as the patient ( $n=10$, mean age: 58 years) showed a span of 5 under any condition. Although we did not repeatedly examine the controls, achieving nearly the same score, either visual or auditory, equivalent to the average digit span score of 5 of the same age group in the Wechsler Memory Scale-Revised (WMS-R) suggests the validity of the test.

Five sets of stimuli were given for one digit or letter sequence, and 0.2 points was given for a correct response. Visual memory span in the WMS-R was also tested, and 0.5 points was given for a correct response. The results showed that auditory and visual letter spans were relatively impaired. Although a digit span score of 6 was considered normal, the score improved to 7 after 2 years (Table 2, described later), suggesting that the patient's digit span had decreased at disease onset.

Calculation Test (Table 3). Previous studies on frontal agraphia reported the cooccurrence of agraphia and acalculia $[3,4]$. Therefore, we conducted a total of 40 calculation tasks [3], including an equal number of addition, subtraction, multiplication, and division with two- and one-digit numbers. Three conditions were provided, that is, mental arithmetic (a patient calculates mentally the tasks read aloud by an examiner), dictated calculation (a patient writes down the calculation tasks read by an examiner and calculates on paper), and calculation using a scientific calculator. The results showed that mental arithmetic was minimally disturbed compared with dictated calculation. Considering that verbal short-term memory or working memory is more closely involved with mental arithmetic than dictated calculation, the difference in the score between mental arithmetic and dictated calculation may have been caused by impaired verbal short-term memory. 


\section{Case Reports in Neurology}

Case Rep Neurol 2018;10:72-82

DOI: $10.1159 / 000487849$

\section{(c)}

(C) 2018 The Author(s). Published by S. Karger AG, Basel www.karger.com/crn

Sakurai et al.: Damage to Precentral Gyrus Causes Phonological Agraphia and Acalculia

Reading and Writing Test (Table 3). Reading and writing of 100 single-character kanji (Japanese morphograms) and the kana transcription of kanji characters [5] were given. All of the kanji characters are taught in the first 3 years of primary school in Japan. The patient achieved nearly perfect scores in both reading and writing, although he spent more time in reading and writing, for both kanji and kana, at onset compared with 10 months later.

Writing Test (Table 3). Writing from dictation of the 50 three-character kana words and nonwords and 50 five-character kana words and nonwords [6] were tested. Three- and fivecharacter words were selected from high familiarity words in former studies that were reevaluated as highly familiar by a recent research study (mean familiarity value in auditory presentation assessed with a 7-point rating scale: 6.09 for the three-character words and 5.81 for the five-character words) [7], and nonwords were made by changing the sequential order of characters in the three- or five-character words. The patient achieved poor scores only for five-character kana nonwords. He was aware that heard sounds for characters disappeared too rapidly to retrieve. He thus pronounced character sequences to write them down in dictation. Errors consisted of nine phonological errors (substitution of another kana character due to consonant or vowel change), and one transposition (the order of successive two-letter sequences transposed with each other) (footnote of Table 3; Fig. 3). He needed more time to complete the five-character kana nonword writing test at onset compared with 6 and 12 months later.

After 6 months, scores for the five-character kana nonword writing and digit span remained unchanged, whereas auditory and visual letter span scores increased by 1 point each. Mental arithmetic and operation with scientific calculator became perfect at 8 months after onset. Twelve months later, the auditory letter span score further increased to 6 (Table 2). Fourteen months later, five-character kana nonword writing improved to $47 / 50$ (footnote of Table 3). The auditory digit span score increased to 7 , and the visual digit span increased to 8 at 24 months after onset (Table 2). Local hypoperfusion of the left sensorimotor cortex recovered in six months after onset (Fig. 2). Although there appeared to be several additional regions of hypoperfusion, including the supramarginal and orbital gyri, this hypoperfusion was not considered pathologically significant because agraphia, acalculia, and working memory impairment did not show any worsening.

\section{Discussion}

The patient presented with transient dysarthria and a minimal writing disorder after a hemorrhage in the left opercular part of the precentral gyrus. Detailed neuropsychological tests revealed minor agraphia for five-character kana nonwords, minimal acalculia (mental arithmetic difficulties), and impaired verbal short-term memory as evaluated by digit and letter spans. Mental arithmetic normalized after 8 months and agraphia recovered to the normal range at 1 year after onset, in parallel with improvement of the auditory letter span from 4 to 6 over a period of 14 months and digit span from 6 to 7 over 24 months. These results suggest a close relationship between the recovery of agraphia and acalculia and the improvement of verbal short-term memory.

The WAB showed a result of 10/10 for writing abilities (Table 1), which is inconsistent with a diagnosis of agraphia. The reason why the battery did not detect agraphia is that it 


\section{Case Reports in Neurology}

Case Rep Neurol 2018;10:72-82

DOI: $10.1159 / 000487849$

\section{(c)}

2018 The Author(s). Published by S. Karger AG, Basel www.karger.com/crn

Sakurai et al.: Damage to Precentral Gyrus Causes Phonological Agraphia and Acalculia

does not assess (kana) nonword writing. The patient's deficit became clear in another test that required kana nonword writing (Table 3). The fact that he needed more time to complete the writing test at onset compared with 6 months or later also suggested the existence of writing difficulties.

None of the patient's data in Table 2 was significantly inferior to those of the healthy controls. One possible reason for this minimal impairment was that the patient was highly educated, working as a professional writer. Despite that, it is conceivable that impaired verbal short-term memory (digit or letter span) affected the patient's mental arithmetic and dictated nonword writing performances simultaneously. The patient's digit span score improved from 6 to 7 over a period of 2 years, and the letter span score improved from 4 to 6 over 14 months. These facts suggest that digit and letter spans were impaired at disease onset. Thus, the phonological errors in kana writing and mental arithmetic difficulties could be explained by a reduced auditory letter or digit span.

Whereas verbal short-term memory is known to be impaired in the left supramarginal and angular gyrus lesions [8], it was also impaired in the frontal lobe damage, that is, Broca aphasia [9], apraxia of speech [9], and agraphia caused by the posterior middle frontal gyrus lesion (Exner area) [3, 4]. Our patient is probably the first case to show that restricted damage to the opercular part of the precentral gyrus causes reduced working memory and phonological agraphia.

Damage to the opercular part of the precentral gyrus is known to cause apraxia of speech [10]. A few more anterior lesions involving the pars opercularis of the Broca area (area 44) have been reported to cause phonological agraphia [11], agraphia for Romaji (an alphabetic writing system for typing in the Japanese language, e.g., "ka" for か) [12], and dystypia (typing impairment) [13]. Furthermore, our patient showed that subcortical damage to the opercular part of the precentral gyrus causes phonological agraphia. This suggests that the inferior part of the precentral gyrus constitutes the phonological route in writing.

The patient's lesion site, the opercular portion of the precentral gyrus, is an endpoint of the arcuate fasciculus [14] that may convey phonological information of a word or syllable sequences from the Wernicke area via the supramarginal gyrus (storage site for verbal short-term memory) to the frontal lobe. Thus, it is probable that damage to the inferior part of the precentral gyrus interfered with the transmission of verbal short-term memory, which particularly affected the spelling of nonwords and mental arithmetic.

Writing requires at least three sources of information: phonological information of a word, the whole-word graphic image that is converted from phonemes in the temporoparietal area [15], and the visuokinesthetic information. These three components are probably transmitted from the temporal and parietal lobes to the frontal lobe and linked together in the premotor area to be sent to the motor hand area to produce spelling or typing. The posterior middle frontal gyrus (Exner area) is another endpoint of the arcuate fasciculus or superior longitudinal fasciculus. Its damage has reportedly caused agraphia of kanji or lexical agraphia (selective impairment of irregular word spelling) [3] as well as kana paragraphia or phonological agraphia [3, 4], and agraphia was more marked than in the present case. Taken together, it is possible that the Exner area links phonemes to graphic images or to visuokinesthetic information and conveys this information to the motor hand area where sequential motor patterns innervating limb muscles are stored. 
The role of the pars opercularis (area 44) in combining phonemes with graphic images and visuokinesthetic information remains unknown. Further study is needed to clarify the functional segregation of the pars opercularis (area 44), the opercular part of the precentral gyrus (area 6), and the posterior middle frontal gyrus (Exner area) in writing and spelling.

\section{Statement of Ethics}

The study protocol was approved by the research ethics committee of our hospital. The patient gave written informed consent.

\section{Disclosure Statement}

The authors report no conflicts of interest.

\section{References}

1 Alexander MP, Friedman RB, Loverso F, Fischer RS: Lesion localization of phonological agraphia. Brain Lang 1992;43:83-95.

2 Cohen J, MacWhinney B, Flatt M, Provost J: PsyScope: an interactive graphic system for designing and controlling experiments in the psychology laboratory using Macintosh computers. Behav Res Methods Instrum Comput 1993;25:257-271.

3 Sakurai Y, Matsumura K, Iwatsubo T, Momose T: Frontal pure agraphia for kanji or kana: dissociation between morphology and phonology. Neurology 1997;49:946-952.

-4 Tohgi H, Saitoh K, Takahashi S, Takahashi H, Utsugisawa K, Yonezawa H, Hatano K, Sasaki T: Agraphia and acalculia after a left prefrontal (F1, F2) infarction. J Neurol Neurosurg Psychiatry 1995;58:629632.

5 Sakurai Y, Sakai K, Sakuta M, Iwata M: Naming difficulties in alexia with agraphia for kanji after a left posterior inferior temporal lesion. J Neurol Neurosurg Psychiatry 1994;57:609-613.

6 Sakurai Y, Asami M, Mannen T: Alexia and agraphia with lesions of the angular and supramarginal gyri: evidence for the disruption of sequential processing. J Neurol Sci 2010;288:25-33.

7 Amano S, Kondo T: NTT Data Base Series. Lexical Properties of Japanese. Tokyo, Sanseido, 2000.

-8 Sakurai Y, Takeuchi S, Kojima E, Yazawa I, Murayama S, Kaga K, Momose T, Nakase H, Sakuta M, Kanazawa I: Mechanism of short-term memory and repetition in conduction aphasia and related cognitive disorders: a neuropsychological, audiological and neuroimaging study. J Neurol Sci 1998;154:182-193.

9 Soma Y: Conduction aphasia and short-term memory. Shitsugoshou Kenkyu 1992;12:145-152.

-10 Tanji K, Suzuki K, Yamadori A, Tabuchi M, Endo K, Fujii T, Itoyama Y: Pure anarthria with predominantly sequencing errors in phoneme articulation: a case report. Cortex 2001;37:671-678. Marien P, Pickut BA, Engelborghs S, Martin JJ, De Deyn PP: Phonological agraphia following a focal anterior insulo-opercular infarction. Neuropsychologia 2001;39:845-855.

$\checkmark 12$ Ogura K, Fujii T, Suzuki K, Mori E: Pure agraphia in Romaji after left inferior frontal gyrus infarction: a case of selective deficit in syllable-to-grapheme conversion in Japanese. Brain Lang 2013;127:1-5.

13 Otsuki M, Soma Y, Arihiro S, Watanabe Y, Moriwaki H, Naritomi H: Dystypia: isolated typing impairment without aphasia, apraxia or visuospatial impairment. Eur Neurol 2002;47:136-140.

14 Bernal B, Altman N: The connectivity of the superior longitudinal fasciculus: a tractography DTI study. Magn Reson Imaging 2010;28:217-225.

15 Sakurai Y, Onuma Y, Nakazawa G, Ugawa Y, Momose T, Tsuji S, Mannen T: Parietal dysgraphia: characterization of abnormal writing stroke sequences, character formation and character recall. Behav Neurol 2007;18:99-114. 


\section{Case Reports in Neurology}

\begin{tabular}{l|l}
\hline Case Rep Neurol 2018;10:72-82 \\
\hline DOI: $10.1159 / 000487849$ & $\begin{array}{l}\text { C } 2018 \text { The Author(s). Published by S. Karger AG, Basel } \\
\text { www.karger.com/crn }\end{array}$ \\
\hline
\end{tabular}

Sakurai et al.: Damage to Precentral Gyrus Causes Phonological Agraphia and Acalculia
16 Matsuda H, MizumuraS, Soma T, Takemura N: Conversion of brain SPECT images between different collimators and reconstruction processes for analysis using statistical parametric mapping. Nucl Med Commun 2004;25:67-74.
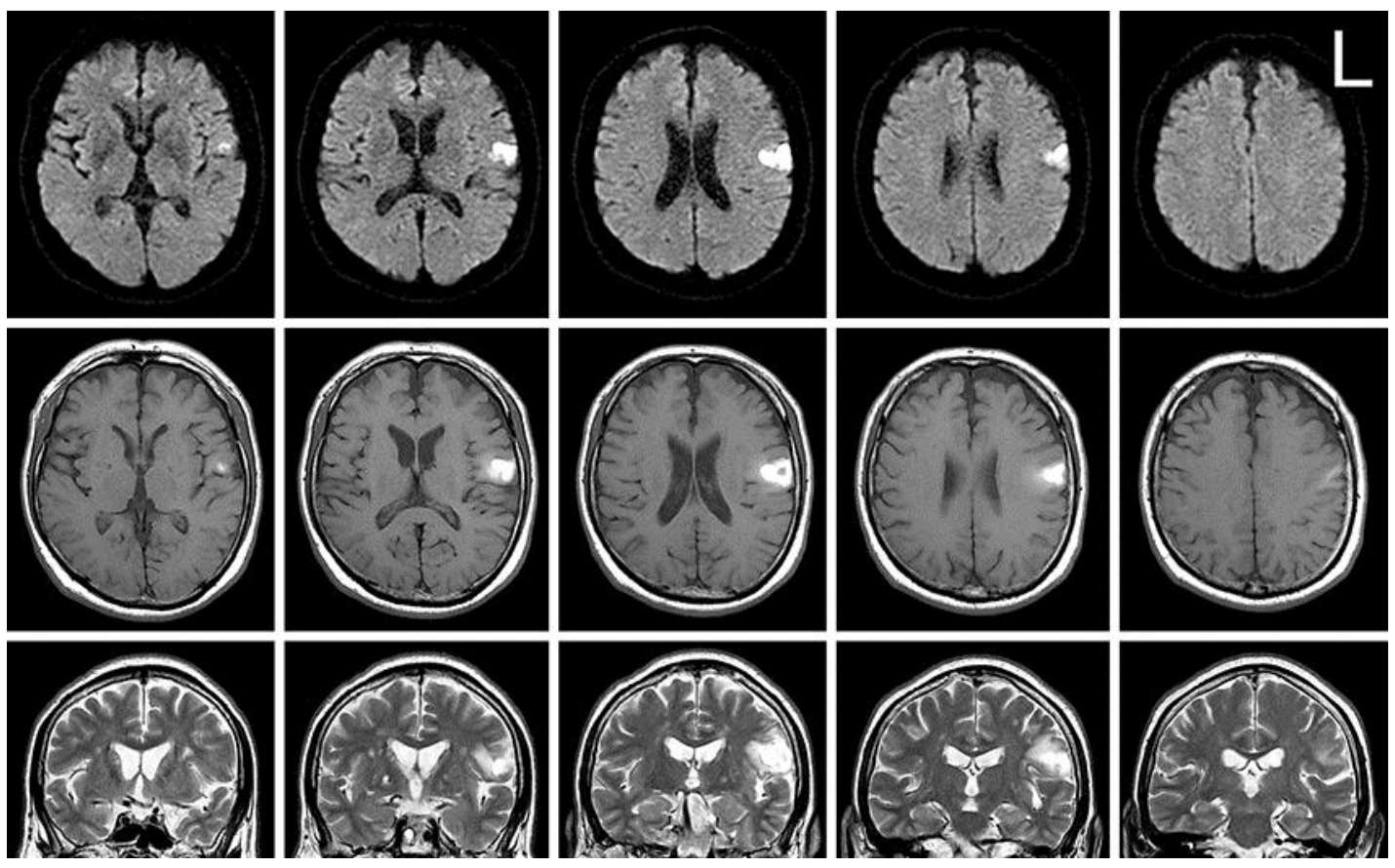

Fig. 1. MR images at 13 days after onset. Diffusion-weighted axial (upper), T1-weighted axial (middle), and T2-weighted coronal (lower) images showed a hyperintense area, suggesting hemorrhage, under the opercular part of the left precentral gyrus (area 6) that extended upward under the postcentral gyrus. T2weighted images also showed old lacunar infarctions in the basal ganglia and periventricular white matter bilaterally. 


\section{Case Reports in Neurology}

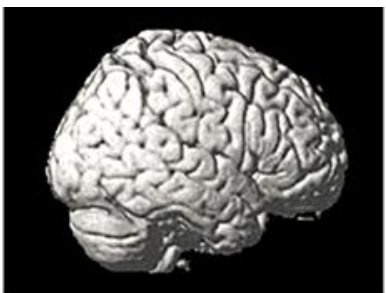

15 days

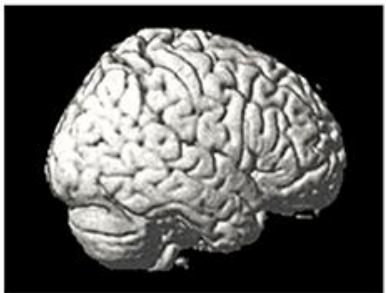

\section{6 months}
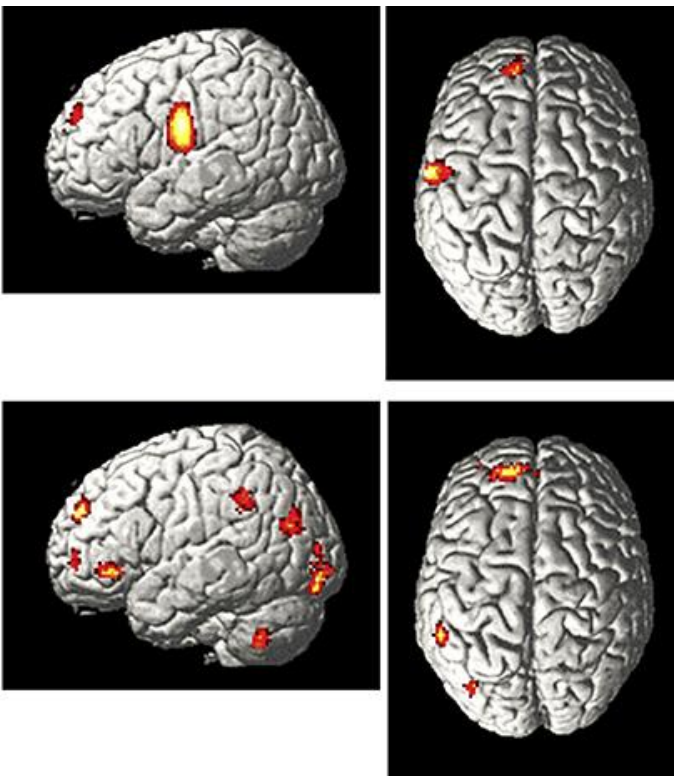

Fig. 2. ${ }^{99 m}$ Tc- ECD-SPECT images at 15 days (upper panel) and 6 months (lower panel) after onset. Regional hypoperfusion is depicted in color. The red-to-bright yellow color gradient reflects increasing Z-scores. A circumscribed area of blood flow reduction in the inferior part of the left sensorimotor cortex was noted at 15 days after onset (upper panel): areas with local maximum reduction in the Montreal Neurological Institute coordinate were area $3(-58,-12,24)$ and area $43(-58,-14,16)$. The local hypoperfusion had recovered at 6 months after onset (lower panel). The image data were first normalized, smoothed, and adjusted to compare between laboratories with the easy Z-score Imaging System (eZIS version 3.4 [16]) , and were constructed using a two-sample $t$ test: patient vs. healthy subjects aged between 40 and 59 years $(n=30)$ (uncorrected $p<0.001$ ) in Statistical Parametric Mapping version 2 (SPM2). The extent threshold was set as equal to the expected voxels per cluster to avoid noise clusters. 


\section{Case Reports in Neurology}

(C) 2018 The Author(s). Published by S. Karger AG, Basel

Sakurai et al.: Damage to Precentral Gyrus Causes Phonological Agraphia and Acalculia www.karger.com/crn
Print

Phonological error: consonant change

りいかれわ

(ri-i-ka-re-wa)

Phonological error: vowel change

んいけしつ

(N-i-ke-shi-tsu)

Transposition error

んかくにみ

$(\mathrm{N}-\mathrm{ka}-\mathrm{ku}-\mathrm{ni}-\mathrm{mi})$
Patient's writing

$$
\begin{aligned}
& \lambda_{1} \cdot \text { th } \\
& (k i-i-k a-r e-w a)
\end{aligned}
$$

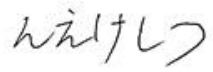

(N-e-ke-shi-tsu)

んかくみに

(N-ka-ku-mi-ni)

Fig. 3. Samples of errors in the five-character kana nonword writing test. Correct answers were illustrated as print characters. Pronunciation of the kana nonword was expressed, with each character being connected with a hyphen (in parenthesis). A phonological error denotes the substitution of another kana character due to consonant change (り[ri] $\rightarrow$ き[ki]) or vowel change (い[i] $\rightarrow$ え[e]). A transposition error denotes changing the sequential order of two kana characters (にみ[nimi] $\rightarrow$ みに[mini]). 
Table 1. Scores for the standard neuropsychological tests at disease onset

\begin{tabular}{ll} 
WAIS-III & \\
Verbal IQ & 139 \\
$\quad$ Digit span forward (raw score) & 6 \\
Performance IQ & 112 \\
Working memory & 130 \\
Processing speed & 105 \\
\hline WAB & \\
Spontaneous speech & \\
$\quad$ Information content $(/ 10)$ & 10 \\
$\quad$ Fluency $(/ 10)$ & 10 \\
Naming total $(/ 10)$ & 9.8 \\
$\quad$ Object naming $(/ 60)$ & 60 \\
Repetition $(/ 10)$ & 10 \\
Comprehension total $(/ 10)$ & 9.75 \\
Reading total $(/ 10)$ & 10 \\
Writing total $(/ 10)$ & 10 \\
Calculation $(/ 24)$ & 24 \\
Praxis $(/ 10)$ & $\mathrm{R} 10$, \\
& $\mathrm{L} 10$ \\
\hline
\end{tabular}

WAIS-III, Wechsler Adult Intelligence Scale-III; WAB, Western Aphasia Battery.

Table 2. Specific neuropsychological tests: digit and letter span forward

\begin{tabular}{llllll}
\hline & Onset & 6 months & 14 months & 24 months & $\begin{array}{l}\text { Controls }^{\mathrm{a}} \text {, } \\
\text { mean score (SD) }\end{array}$ \\
\hline Auditory digit span & $6.8(94)$ & $6.0(91)$ & $6.2(92)$ & $7.0(95)$ & $5.28(1.15)$ \\
Visual digit span & $6.0(88)$ & $6.2(90)$ & $6.4(91)$ & $8.0(97)$ & $5.38(1.34)$ \\
Auditory letter span & $4.4(11)$ & $5.2(78)$ & $6.0(89)$ & $5.6(83)$ & $4.9(0.74)$ \\
Visual letter span & $5.4(74)$ & $6.2(90)$ & $6.2(90)$ & $6.0(89)$ & $5.2(1.07)$ \\
Visual memory span (WMS-R) & $6.0(90)$ & $6.5(96)$ & $6.5(96)$ & $5.5(74)$ & $5(56$ percentile) \\
\hline Data are presented as raw score (percentile) unless otherwise indicated. a Healthy controls $(n=10)$ at around the same \\
age were 8 men and 2 women, age range: 51-64 years, mean: 58 years. based on the Manual for the Wechsler Memory \\
Scale-Revised (WMS-R, Japanese edition), $n=50$, age range: 55-64 years. \\
\hline
\end{tabular}


Table 3. Specific neuropsychological tests: calculation, reading, and writing

\begin{tabular}{|c|c|c|c|c|}
\hline & \multirow[t]{2}{*}{ Onset } & \multirow[t]{2}{*}{$6-10$ months } & \multicolumn{2}{|l|}{ Controlsa } \\
\hline & & & mean score (SD) & mean time $(\mathrm{SD})$ \\
\hline \multicolumn{5}{|c|}{ Calculation (follow-up 8 months after onset) } \\
\hline Mental arithmetic $(/ 40)$ & $38(68)^{\mathrm{b}}$ & $40(99)$ & $36.25(2.73)$ & \\
\hline Dictated calculation $(/ 40)$ & $40(>55)$ & $40(>55)$ & $39.25(0.96)$ & \\
\hline Scientific calculator $(/ 40)$ & $39(<10)$ & $40(>19)$ & $39.83(0.97)$ & \\
\hline \multicolumn{5}{|c|}{ Reading and writing (follow-up 10 months after onset) } \\
\hline \multirow[t]{2}{*}{ Kanji reading $(/ 100)$} & $100(>9)$ & $100(>9)$ & $99.6(1.2)$ & $1 \mathrm{~min} 32 \mathrm{~s}(32 \mathrm{~s})$ \\
\hline & $2 \min 11 \mathrm{~s}(91)$ & $60 \mathrm{~s}(9)$ & & \\
\hline \multirow[t]{2}{*}{ Kana reading $(/ 100)$} & $99(90)$ & $100(99)$ & $99.6(0.5)$ & $1 \min 13 \mathrm{~s}(24 \mathrm{~s})$ \\
\hline & $1 \min 16 \mathrm{~s}(64)$ & $51 \mathrm{~s}(15)$ & & \\
\hline \multirow[t]{2}{*}{ Kanji writing (/100) } & $100(99)$ & $99(90)$ & $95.9(3.0)$ & $10 \min 11 \mathrm{~s}(136 \mathrm{~s})$ \\
\hline & $8 \min 47 \mathrm{~s}(27)$ & $7 \min 21 s(12)$ & & \\
\hline \multirow[t]{2}{*}{ Kana writing (/100) } & $100(>40)$ & $100(>40)$ & $99.3(0.9)$ & $8 \min 7 s(107 s)$ \\
\hline & $6 \min 52 \mathrm{~s}(27)$ & $5 \min 59 \mathrm{~s}(14)$ & & \\
\hline \multicolumn{5}{|l|}{ Writing (follow-up 6 months after onset) } \\
\hline \multirow[t]{2}{*}{ Three-character kana words (/50) } & $50(10)$ & nd & $49.7(0.9)$ & $3 \min 50 s(66 s)$ \\
\hline & $4 \min 24 \mathrm{~s}(71)$ & & & \\
\hline \multirow[t]{2}{*}{ Three-character kana nonwords (/50) } & $50(60)$ & nd & $48.9(1.3)$ & $4 \min 6 s(76 s)$ \\
\hline & $5 \min 12 \mathrm{~s}(70)$ & & & \\
\hline \multirow[t]{2}{*}{ Five-character kana words (/50) } & $50(>44)$ & nd & $49.5(0.7)$ & $6 \min 4 \mathrm{~s}(89 \mathrm{~s})$ \\
\hline & $6 \min 3 s(67)$ & & & \\
\hline \multirow[t]{2}{*}{ Five-character kana nonwords (/50) } & $40(90)^{\mathrm{c}}$ & $37(77)^{d}$ & $36.2(5.3)$ & $7 \min 49 \mathrm{~s}(117 \mathrm{~s})$ \\
\hline & $9 \min 31 s(83)$ & $7 \min 28 s(41)$ & & \\
\hline
\end{tabular}

Data are presented as raw score and time (percentile). a Healthy controls: calculation, $n=12$ (7 men and 5 women), age range: $64-80$ years, mean: 67 years; reading and writing (100 words), $n=11$ (10 men and 1 woman), age range: $61-78$ years, mean: 68 years; writing ( 50 three-character words), $n=11$ ( 6 men and 5 women), age range: $65-86$ years, mean: 73 years; writing (50 five-character words), $n=10$ ( 4 men and 6 women), age range: 71-80 years, mean: 74 years; all with 9 or more years of education and no past history of neurologic illness. b Errors included 1 subtraction (97 $-6=92)$ and 1 division (68 $\div$ $2=39$ ) task. c Errors consisted of 9 phonological errors (consonant change 8, vowel change 1) and 1 transposition (the order of successive two-letter sequences is transposed with each other). See Figure 3, for examples. $d$ The score and time improved to 47 (99 percentile) and $6 \mathrm{~min} 37 \mathrm{~s}$ (33 percentile) at 1 year after onset. nd, not done. 